Daniela Solzbacher · Franz-Georg Hanisch

Loek van Alphen · Janet R. Gilsdorf · Horst Schroten

\title{
Mucin in middle ear effusions inhibits attachment of Haemophilus influenzae to mucosal epithelial cells
}

Received: 21 June 2002 / Accepted: 9 August 2002 / Published online: 3 October 2002

(C) Springer-Verlag 2002

\begin{abstract}
Although otitis media with effusion is often preceded by an infection of the tympanic cavity, when cultured, many effusions show no culturable bacteria. Based on the hypothesis that the effusion might play a protective role in the course of infection, the influence of this fluid on adhesion of $H$. influenzae (Hi) type-b strain 770235 and nontypeable $H$. influenaze (NTHi) strains to buccal epithelial cells was investigated. Effusions were classified as mucoid, seromucoid and serous. Mucoid secretions inhibited adhesion to a significantly greater extent $(62 \%)$ than did seromucous $(52 \%)$ and serous effusions $(47 \%)$ $(P<0.001)$. The glycoprotein and high-molecular-weight fractions showed similar levels of inhibition. Sialic acid concentration, and, to a lesser extent, protein concentration, correlated with the level of inhibition. Desialylated effusions lost their ability to block bacterial attachment. Thus, middle ear effusion fluid exhibits an inhibitory effect that is due to mucins, which determine viscosity and represent the sialylated high-molecular-weight glycoprotein fraction of the effusion.
\end{abstract}

Keywords Mucin · Bacterial adhesion · Otitis media

D. Solzbacher

Department of Otorhinolaryngology, University of Essen,

Essen, Germany

F.-G. Hanisch

Institute of Biochemistry, Medical Faculty,

University of Cologne, Cologne, Germany

L. van Alphen

National Institute for Public Health and the Environment,

Bilthoven, The Netherlands

J.R. Gilsdorf

Department of Pediatrics, University of Michigan Medical School, Ann Arbor, Michigan, USA

H. Schroten (

University Children's Hospital,

Moorenstr. 5, 40225 Düsseldorf, Germany

e-mail: schroten@uni-duesseldorf.de,

Tel.: +49-211-8117687, Fax: +49-211-8119514

\section{Introduction}

Otitis media with effusion (OME) is defined as an accumulation of fluid behind an intact tympanic membrane without acute signs or symptoms of infection. Between $54-86 \%$ of children experience at least one episode of acute otitis media by the age of 2 years, and middle ear effusions (MEEs) occur in up to $90 \%$ of children by that age $[1,2]$. The cause of OME has been a matter of debate and is still not completely understood. It seems to be multifactorial, with eustachian tube dysfunction, viral or bacterial infection or both being important factors. Edema of the tubal orifice, as can be found in pharyngitis or allergic rhinitis, or malfunction of the eustachian tube, as in cleft palate or other craniophraryngeal malformations, may lead to failure of drainage of normally produced middle ear secretions. It has also been postulated that OME is simply a continuum of acute otitis media [3], with effusion remaining after bacteria have been cleared. The effusion develops in association with inflammatory changes of the mucosa lining the middle ear cavity. It has recently been suggested that the inflammatory stimuli are bacterial components, such as lipopolysaccharides, which stimulate TNF-alpha production and thereby induce mucous hyperplasia and mucin production mediated by nitric oxide [2, $4,5,6]$. In OME a metaplastic change of the normally columnar respiratory epithelium into a secretory-type epithelium with proliferation of goblet cells and mucus glands occurs [7, 8], and the result is the accumulation of fluid in the middle ear cavity.

Some authors report that bacteria can be found in up to $52 \%$ of patients with MEE and that with longer persistence bacteria are less likely to be cultured from MEE [3]. Other investigators found the fluids to be sterile in up to 92\% of the cases [9]. Haemophilus influenzae, Streptococcus pneumoniae and Moraxella catarrhalis are the most commonly isolated pathogens, and Haemophilus influenzae has been shown to be predominant in recurrent disease [10]. Since attachment of bacteria to respiratory cells is a necessary prerequisite for infection, we investi- 
gated the ability of different Hi strains to adhere to buccal epithelial cells and the role of MEEs in blocking bacterial adhesion.

We hypothesized that MEEs not only cause hearing impairment and consequently a delay in speech development, but also could play an anti-infective role. From previous studies we knew that the sugar residues on mucin molecules can play a protective role in the course of infection. Our aim in this study was to investigate the effect that MEEs, and particularly the mucins in the effusions, have on bacterial adhesion.

\section{Materials and methods}

Sixty-six MEE samples were collected from 44 children (23 male, 21 female) during tympanostomy under the control of an operating microscope without sterilization of the ear canal. The MEE samples were aspirated into a Tym-Tap collector (Juhn Tym-Tap, Xomed, Inc.) The age of the children ranged from 1 to 9 years (mean $=4.96$ years). Effusions were classified into mucoid, seromucoid and serous, as described by Carrie et al. [11] on the basis of their physical appearance and their ability to flow on inversion.

\section{Testing for bacterial contamination}

Within $4 \mathrm{~h}$ after aspiration the samples were tested for bacterial contamination. Sterile loops were dipped in undiluted MEEs. The lower limit of detection of bacterial contamination was about $100 \mathrm{bacteria} / \mathrm{ml}$. A calibrated loop was used for testing the samples.

The specimens were plated on chocolate and sheep blood agar. Identification of bacterial species was performed according to standard laboratory methods. No antibiotics had been administered within 2 weeks prior to myringotomy.

\section{Pretreatment of the MEEs}

The volume of the samples ranged from 20 to $250 \mu \mathrm{l}$ (mean= $97.15 \mu \mathrm{l})$. All MEE samples were kept frozen prior to use. To liquefy the highly viscous fluids, a saline solution containing $8 \mathrm{M}$ guanidin- $\mathrm{HCl}, 2 \mathrm{mM}$ dithiothreitol, $2 \mathrm{mM}$ EDTA and $2 \mathrm{mM}$ sodium phosphate was added to each sample at equal volumes and left at room temperature overnight. To wash out the added substances, the MEEs were placed on Sephadex G25 columns (NAP-5, Pharmacia Biotech, Freiburg, Germany) and eluted with $1 \mathrm{ml}$ $0.01 \mathrm{M}$ phosphate-buffered saline (PBS). All samples, regardless of viscosity, were treated as described above to create equal conditions. The added substances do not alter the receptoranalog structures on the mucin molecule, the component of the effusions that we focused on. Other proteins could possibly become reduced or denaturated so that no comment can be made about their additional effect on bacterial adhesion.

\section{Buccal epithelial cells (BECs)}

Due to the unavailability of human middle ear mucosal cells and the various unfavorable characteristics of cell lines, we decided to use BECs, representing human mucosal epithelial cells. BECs were obtained by gently scraping the buccal mucosa of a healthy adult nonsmoker with a spoon. BECs were washed three times in $0.01 \mathrm{M}$ PBS containing $0.1 \%$ bovine serum albumin (BSA) and then re-suspended in the same buffer to $1 \times 10^{5} \mathrm{BEC} / \mathrm{ml}$.

\section{Bacteria}

Due to the different use of terms in the literature, the filamentous structures will be referred to as fimbriae on type-b $H$. influenzae (Hib) and as pili on NTHi throughout the manuscript.

The following strains were used in the adherence assays: four capsule and fimbrial variants of Hib strain 770235, i.e., fimbriated and nonencapsulated $\left(\mathrm{f}^{+} \mathrm{b}^{\circ}\right)$, fimbriated and encapsulated $\left(\mathrm{f}^{+} \mathrm{b}^{+}\right)$, nonfimbriated and nonencapsulated $\left(\mathrm{f}^{\circ} \mathrm{b}^{\circ}\right)$, nonfimbriated and encapsulated $\left(\mathrm{f}^{\circ} \mathrm{b}^{+}\right)$and piliated $(\mathrm{p}+)$ and nonpiliated $(\mathrm{p}-)$ phase variants of the NTHi strains AAR 45, AAR 91 and AAR 176 [12, 13]. The strains were stored frozen at $-70^{\circ} \mathrm{C}$ in aliquots in $\mathrm{BHI}$ medium and $10 \%$ glycerol. They were taken from the frozen stocks for each adhesion experiment and grown on chocolate agar plates overnight under candle-jar atmosphere at $37^{\circ} \mathrm{C}$. The bacteria were washed three times and incubated with fluorescein-isothiocyanate (FITC) for $30 \mathrm{~min}$ at $23^{\circ} \mathrm{C}$. After removal of unbound FITC, the bacteria were suspended in $0.01 \mathrm{M}$ PBS to $2 \times 10^{8}$ bacteria $/ \mathrm{ml}$.

\section{Adherence assay}

One hundred $\mu \mathrm{l}$ of bacteria were incubated with $100 \mu \mathrm{l}$ of a potential inhibitor for $30 \mathrm{~min}$ at $4^{\circ} \mathrm{C}$ [14]. Preliminary experiments showed increased variability of the results at a shorter incubation time of $15 \mathrm{~min}$. The following substances were tested as inhibitors: mucoid, seromucoid and serous MEEs (serial two fold dilution to $1: 8)$, the glycoprotein fraction of the MEEs, the high-molecularweight fraction of the MEEs, desialylated MEEs, MEEs that were heated to $95^{\circ} \mathrm{C}$ for $10 \mathrm{~min}$ to disrupt the immunoglobulin, purified MUC1 from human milk and various negatively charged substances, such as dextran sulfate, hyaluronic acid, chondroitin sulfate (Serva, Heidelberg, Germany), fucoidan (Sigma Chemical Co., St. Louis), polygalacturonic acid (Paesel KG, Frankfurt) and sialic acid. Skimmed human milk was used as a control [14]. Two hundred $\mu \mathrm{l}$ of the BECs were added and incubated with bacteria and inhibitor for $60 \mathrm{~min}$ at $4^{\circ} \mathrm{C}$ (ratio BECs/bacteria was 1:1,000). The suspension was washed twice, and the adherent bacteria to 50 BECs were counted using a fluorescence microscope (Zeiss, Jena, Germany). All experiments were carried out at least in duplicate.

Measurement of protein, sialic acid, immunoglobulin A ( $\operatorname{IgA})$ and mucin

The protein content was measured according to the method of Lowry [15] using BSA as a standard. The sialic acid concentration was determined using the periodate-resorcinol method for microtiter plate readers [16]. IgA concentration was measured by radial immunodiffusion on LC-Partigen disks (Dade Behring, Schwalbach, Germany).

The presence of MUC1 in the effusions was determined by use of a $2 \times$ Alkaline Phosphatase-Anti-Alkaline Phosphatase (APAAP)ELISA, which is described elsewhere [17]. After antigen immobilization with $50 \mu \mathrm{l}$ coating buffer, the mouse antibody BC-3 $(1: 1,000)$ was incubated at $37^{\circ} \mathrm{C}$ for $2 \mathrm{~h}$ and washed twice. The antibody Z259 was added and incubated for $30 \mathrm{~min}$ at room temperature. After an incubation period of $30 \mathrm{~min}$ with APAAP solution, $\mathrm{Z} 259$ was added again and incubated for $20 \mathrm{~min}$. A solution containing $1 \mathrm{mg} / \mathrm{ml}$ p-nitrophenylphosphate in diethanolamine buffer was added, incubated and measured in an ELISA reader at $405 \mathrm{~nm}$. MUC1 isolated from human milk fat globules was used as a positive control [18]. Z259 is a polyclonal rabbit anti-mouse Ig, which serves as a bridging antibody between the primary mouse antiMUC1 (BC-3) and a mouse anti-alkaline phosphatase complexed with the enzyme (APAAP). The BC-3 antibody (Ian McKenzie, Austin Research Institute, Heidelberg, Australia) recognizes specifically the tandem repeats of all MUC1 glycoforms. 
Glycoprotein isolation

The glycoprotein fraction of the MEEs was obtained by phenol extraction as described by Uhlenbruck et al. [19]. The pretreated MEEs were diluted 1:10 with distilled water, and the same volume of $90 \%$ phenol was added and vortexed until opacity occurred. After an incubation period of $20 \mathrm{~min}$ at $60^{\circ} \mathrm{C}$, the suspension was centrifuged for $30 \mathrm{~min}$ at $2,000 \mathrm{rpm}$. The clear supernatant was dialyzed overnight.

Gel chromatography

Two pooled mucoid effusions were fractionated on a Superdex HR 200 gel filtration column $(1 \times 30 \mathrm{~cm}$, Pharmacia Biotech Freiburg, Germany). The column was eluted with $100 \mathrm{mM}$ sodium-phosphate buffer, and the high-molecular-weight fraction was dialyzed against $0.01 \mathrm{M}$ PBS overnight before being used in the adherence assay.

\section{Sialidase treatment}

Four hundred $\mu \mathrm{l}$ of the pretreated MEEs were incubated with $1 \mathrm{ml}$ Vibrio cholerae neuraminidase $(1 \mathrm{U} / \mathrm{ml})$ for $18 \mathrm{~h}$ at $37^{\circ} \mathrm{C}$ and dialyzed against $0.01 \mathrm{M}$ PBS overnight.

Heat treatment

Two mucoid effusions were heated to $95^{\circ} \mathrm{C}$ in an incubator for $10 \mathrm{~min}$.

Statistical analyses

The findings of inhibition of bacterial attachment to cells in the presence of various inhibitors were compared using the two-sided Wilcoxon rank sum test. Spearman's coefficient of rank correlation was used to analyze correlations between the level of inhibition and the protein and sialic acid concentrations and between the level of inhibition and different dilutions of the MEEs.

\section{Results}

\section{Bacteriological investigation}

Examination of the 66 MEE samples revealed positive cultures in only five cases (7.58\% of all samples) with two samples harboring $H$. influenzae, one showing Moraxella catarrhalis and another two harboring nonpathogens. Contaminated effusions were excluded from further investigation.

\section{Adherence of bacteria to BECs}

In comparing the adhesion ability of the four Hib variants without the addition of an inhibitor, the mean adherence value was $31.82 \pm 6.32$ organisms per epithelial cell for Hib variant $\mathrm{f}^{+} \mathrm{b}^{\circ}(n=38)$ and 29.12 \pm 3.32 for Hib variant $\mathrm{f}^{+} \mathrm{b}^{+}(n=10)$. The nonfimbriated variants showed little adherence with $2.56 \pm 0.35$ bacteria per cell for variant $\mathrm{f}^{\circ} \mathrm{b}^{+}$ $(n=5)$ and $1.02 \pm 0.36$ for variant $\mathrm{f}^{\circ} \mathrm{b}^{\circ}(n=5)$.

NTHi strain $45 p+$ adhered well, showing $24.89 \pm 0.34$ bacteria per cell, and its nonpiliated variant $45 \mathrm{p}$ - showed
$12.98 \pm 3.26$ bacteria per cell. Strain $91 \mathrm{p}+$ adhered with $21.02 \pm 2.07$ bacteria per cell, variant 91 p- with $20.71 \pm$ 6.30. Strain $176 \mathrm{p}+$ showed $22.10 \pm 1.57$, and its nonpiliated variant $176 \mathrm{p}$ - showed $19.24 \pm 1.68$ ( $n=3$ in each case).

\section{Effect of MEEs on adherence}

In Hib variant $\mathrm{f}^{+} \mathrm{b}^{\circ}$, mucoid effusions $(n=18)$ inhibited adherence by $62 \pm 6.03 \%$, and this level of inhibition was significantly higher $(P<0.001)$ than both the effect of seromucoid MEEs $(n=8)$, which inhibited bacterial attachment by $51 \pm 2.24 \%$, and the effect of serous MEEs $(n=8)$ on adherence, which showed $47 \pm 11.38 \%$ inhibition. Using the Hib variant $\mathrm{f}^{+} \mathrm{b}^{+}$in the adherence assay, similar results were obtained with mucoid MEEs $(n=4)$ inhibiting adhesion by $60 \pm 5.58 \%$, seromucoid effusions $(n=3)$ inhibiting by $52 \pm 2.84 \%$ and serous MEEs $(n=3)$ showing $47 \pm 1.60 \%$ inhibition.

The inhibitory effect of MEEs on the attachment of the nonfimbriated Hib variants $\mathrm{f}^{\circ} \mathrm{b}^{+}$, and $\mathrm{f}^{\circ} \mathrm{b}^{\circ}$ could not be assessed because of the low number of adherences in the absence of any inhibitors.

Adhesion of all NTHi strains (piliated and nonpiliated) used in this study was inhibited by mucoid MEEs ( $n=5$ in each case) to a comparable degree, as was the adhesion of Hib variant $\mathrm{f}^{+} \mathrm{b}^{\circ}$ (Fig. 1). The effect of serous MEEs on bacterial adhesion was tested for strain $91 \mathrm{p}+$. An inhibition of $44 \pm 9.22 \%$ was obtained.

The level of inhibition of bacterial adhesion correlated with the dilution of both mucoid $\left(r=0.96\right.$ for Hib $\mathrm{f}^{+} \mathrm{b}^{+}$; $r=0.96$ for $\mathrm{Hib}^{+} b^{0} ; r=0.97$ for NTHi $91 \mathrm{p}+$ and $r=0.94$ for NTHi $91 \mathrm{p}-)$ and serous MEEs $\left(r=0.95 \mathrm{Hib}^{+} b^{+}\right.$; $r=0.97 \mathrm{Hib} \mathrm{f}^{+} \mathrm{b}^{0}$ and $\mathrm{r}=0.97$ for NTHi $91 \mathrm{p}+$ ). Hence, the inhibition of bacterial adhesion could be shown to be a specific effect.

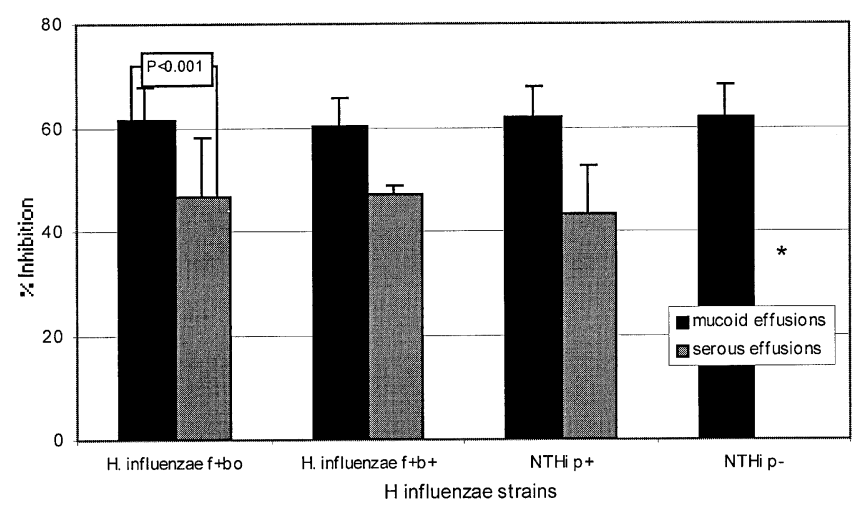

Fig. 1 Inhibition of adhesion of the various strains and variants of $H$. influenzae by mucoid and serous effusions (MEEs) (*serous MEEs not tested for NTHi p-). Data shown are means \pm SDs; statistical significance was determined using the Wilcoxon rank sum test. Equal amounts of mucins according to the ratio of sialic acid vs. protein were used for each type of MEE 


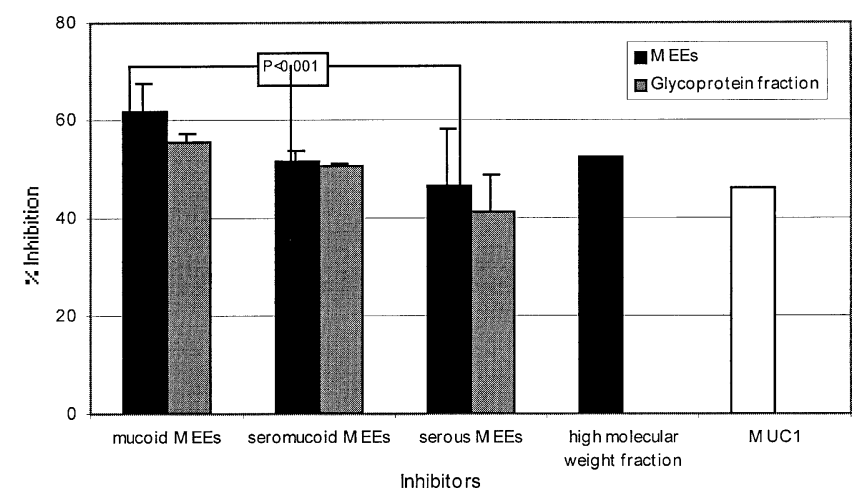

Fig. 2 Influence of the middle ear effusions (MEEs) and their glycoprotein fractions, the effect of the high molecular weight fractions and purified MUC1, respectively, on adherence of $H$. influenzae 770235 variant $\mathrm{f}^{+} \mathrm{b}^{\circ}$ to buccal epithelial cells. Data are means \pm SDs; significance was determined by the Wilcoxon rank sum test

Effect of the glycoprotein fractions on adhesion

Since mucoid MEEs were the best inhibitor of bacterial adherence, the fraction responsible for this effect was sought. The component determining the viscosity of MEEs is mucin [11], which is a high-molecular-weight glycoprotein. Thus, the glycoprotein fraction was isolated and used as a potential inhibitor. The effect of the glycoprotein fractions of the MEEs on bacterial adherence was tested using Hib variant $\mathrm{f}^{+} \mathrm{b}^{\circ}$. The glycoproteins of mucoid, seromucoid and serous MEEs inhibited the attachment of bacteria to a comparable extent, as did the nonfractionated effusions (Fig. 2).

The effect of the glycoprotein fraction of the effusions was also tested for the six NTHi strains, and comparable results were obtained with a mean level of inhibition of $56.99 \pm 3.14 \%$ for the mucoid effusions, $46.58 \pm 3.04 \%$ for the seromucoid and $37.83 \pm 2.83 \%$ for serous MEEs ( $n=2$ in each case).

Inhibition of bacterial adherence by high molecular weight fractions

The eluted high-molecular-weight fraction of two pooled mucoid MEEs was used in the adherence assay and inhibited the adhesion of Hib variant $\mathrm{f}^{+} \mathrm{b}^{\circ}$ by $52.36 \%$ (see Fig. 2) and of all NTHi strains by $50 \pm 3.97 \%$.

\section{Detection of MUC1 in the MEEs}

Using the ELISA technique MUC1 mucin was detected in all the MEEs that were tested $(n=5)$. Mucoid effusions were found to contain more mucin than the serous effusions. Semi-quantitative estimations were based on a calibration curve measured for linearly diluted MUC1 from human milk fat globule membranes, taking into consideration that the primary anti-MUC1 antibody (BC-3) is largely unaffected by the glycoforms of the mucin.
Influence of MUC1 on bacterial adhesion

Purified MUC1 from skimmed human milk was able to block adherence of Hib variant $\mathrm{f}^{+} \mathrm{b}^{\circ}$ by $46.31 \%$ (see Fig. 2). Adhesion of the different NTHi strains could be inhibited to a similar extent with $45 \pm 4.09 \%$.

\section{Protein and sialic acid contents}

The level of inhibition of the Hib variants correlated with the sialic acid concentration of the MEEs $(r=0.84$ for $770235 \mathrm{f}^{+} b^{\mathrm{o}} ; \quad r=0.92$ for $\left.770235 \mathrm{f}^{+} \mathrm{b}^{+}\right)$, and correlation could also be found, although not to such a high degree, between the protein content of the effusion and the level of inhibition of bacterial attachment $(r=0.75$ for 770235 $\mathrm{f}^{+} b^{\circ}$ and $r=0.89$ for $770235 \mathrm{f}^{+} \mathrm{b}^{+}$). The inhibition of adhesion of the NTHi strains also correlated with the sialic acid concentration $(r=0.71$ for piliated NTHi and $r=0.68$ for nonpiliated NTHi) and with the protein concentration of the effusions ( $r=0.40$ for piliated NTHi and $r=0.72$ for nonpiliated NTHi).

Correlation could also be found regarding the influence of the glycoprotein fractions on bacterial adhesion and their protein and sialic acid contents. The inhibition of adherence of Hib variant $\mathrm{f}^{+} \mathrm{b}^{\circ}$ correlated with the sialic acid concentration of the glycoprotein fractions $(r=0.94)$ and with their protein concentration $(r=0.82)$. Inhibition of adhesion of the NTHi strains also correlated with the sialic acid concentration $(r=1.00)$ and with the protein concentration of the fractionated effusions $(r=0.83)$.

Mucoid MEEs contained more sialic acid (382.12 \pm $22.70 \mu \mathrm{g} / \mathrm{ml})$ than seromucoid MEEs $(123.58 \pm 44.64$ $\mu \mathrm{g} / \mathrm{ml})$ and serous MEEs $(96.14 \pm 63.74)$. The protein concentration was also higher in mucoid effusions (6.29 \pm $2.93 \mathrm{mg} / \mathrm{ml})$ than in seromucoid $(3.52 \pm 2.09 \mathrm{mg} / \mathrm{ml})$ and serous effusions $(2.16 \pm 1.72 \mathrm{mg} / \mathrm{ml})$.

\section{Sialidase treatment}

Since the sialic acids seemed to play a certain role in the course of inhibition, two MEEs were desialylated and again used in the adherence assay. Prior to treatment, the effusions inhibited adhesion of the $\mathrm{Hib}^{+} \mathrm{b}^{\circ}$ variant by $75.56 \%$ and $60.61 \%$, respectively, containing 744.44 and $671.65 \mu \mathrm{g} / \mathrm{ml}$ sialic acid. After incubation with Vibrio cholerae neuraminidase, the effusions contained 5.65 and $2.55 \mu \mathrm{g} / \mathrm{ml}$ sialic acid and had completely lost their inhibitory effect on bacterial adhesion (data not shown).

\section{Effect of purified sialic acid on adhesion}

To assess whether the inhibitory effect of the mucins was only due to the sialic acid, we investigated sialic acid and its effect on adherence in the assay. No inhibition of adhesion of any Hi strain was found at concentrations of up to $400 \mu \mathrm{g} / \mathrm{ml}$ (data not shown). 
Effect of other potential inhibitors on adhesion

The carbohydrate chains of the mucin molecule carry sulphate groups and sialic acid residues, which both impart a negative charge. To rule out the possibility that the inhibitory effect could be a matter of charge, several negatively charged substances were tested for their effect on bacterial attachment. Hyaluronic acid, fucoidan and chondroitin sulfate showed no inhibition of attachment of bacteria when added at a concentration of $100 \mu \mathrm{g} / \mathrm{ml}$. Polygalacturonic acid inhibited bacterial adhesion of the Hib variant $\mathrm{f}^{+} \mathrm{b}^{\circ}$ by $20 \%$ and dextran sulfate by $9 \%$ at a concentration of $100 \mu \mathrm{g} / \mathrm{ml}$, whereas no inhibition of bacterial adhesion could be detected regarding NTHi. Higher levels of inhibition could not be obtained by increasing the concentration of the substances to $400 \mu \mathrm{g} / \mathrm{ml}$.

\section{Immunoglobulin A}

Out of the 61 sterile MEEs, 40 gave negative results for IgA by using the radial immunodiffusion method, with a lower detection limit of $0.7 \mathrm{mg} / \mathrm{dl}(0.007 \mathrm{~g} / \mathrm{l})$. In the other 21 effusions, IgA concentrations ranged from 0.8 to $52.4 \mathrm{mg} / \mathrm{dl}$, and those results showed no evidence of correlation with inhibition of bacterial attachment or with affiliation to either of the three subgroups, i.e., mucoid, seromucoid and serous. However, to finally exclude any effect of immunoglobulins on the inhibition of adhesion, two MEE samples were heated to $95^{\circ} \mathrm{C}$ for $10 \mathrm{~min}$. Prior to this treatment, the samples inhibited bacterial attachment by $59 \%$ and $63 \%$. After the heating process, the inhibition was at $57 \%$ and $62 \%$, respectively.

\section{Discussion}

According to the available evidence, otitis media with effusion, a frequent disease in children, is primarily an inflammatory condition. Possible stimuli include viruses, allergies, bacteria and their breakdown products [3]. Bacteria such as $H$. influenzae, Streptoccocus pneumoniae and Moraxella catarrhalis have been cultured from up to $40 \%$ of effusions [2, 20, 21, 22].

We have hypothesized that components of the effusion have anti-infective activity because, in the presence of effusion, signs or symptoms of inflammation are typically absent.

Middle ear effusions consist of water, cells, electrolytes and various high-molecular-weight compounds. The latter include mucins, proteins, lipids and DNA. Secretory mucins are of great interest because of their structural and functional properties. Mucins, the major component of all mucus secreted from epithelial cells, are highly glycosylated, sialic acid-containing proteins linked together by disulfide bridges to form large macromolecular complexes. Due to the polyvalent presentation of receptorana$\log$ structures, mucins are capable of binding bacteria through specific attachment sites [23, 24, 25]. While other components of the effusion such as protein-bound hexosamines, neutral sugars and sialic acid pointed to the origin of the fluid [26], the presence of mucin proves that MEEs are not simply passive transsudates from blood.

Mucins from middle ear effusions have been shown to be similar in composition to mucins from other body sites. Over ten different mucins have been identified so far [27]. In this study we focused on MUC1, which is found, among other places, in the mucosa of the nose and maxillary sinus and the lower airways [2]. Previous studies have identified MUC5AC and MUC5B to be present in middle ear effusions and MUC1 and MUC2 to be absent [28]. We were able, however, to detect MUC1 in all the effusions that were tested.

One explanation for this discrepancy is that Hutton et al. tried to detect MUC1 using the monoclonal antibody NCL-MUC1, which differs from the BC3 monoclonal antibody used in this study. NCL-MUC1 from Novacastra Ltd. is non-reactive to unglycosylated MUC1 tandem repeat peptide and becomes strongly reactive on specific glycoforms of the mucin. $\mathrm{BC} 3$ is a peptide-specific antibody that recognizes the DTR motif within the tandem repeat peptide independently of its glycosylation and thus is better suited for the detection of all glycoforms of MUC1.

In this study we were able to show that the attachment of the fimbriated strains to cells could be inhibited after incubating bacteria with human MEEs. This contrasts the findings of Davies et al. [29], who found that pretreatment of bacteria with mucins did not alter adherence to the epithelial cells, whereas mucin pretreatment of the epithelial cells reduced bacterial adhesion, implying that the receptors on epithelial cells are shielded by mucin. These divergent findings may be explained by differences in the composition of the airway tract mucin [30] used by Davies et al. and the middle ear mucin used by us.

We also found the NTHi strains to adhere well to buccal epithelial cells regardless of piliation. The ability to block this attachment to the cells by preincubation with MEEs was similar for both piliated and nonpiliated strains, which suggests that the inhibitory effect is mediated by blocking nonpilus adhesins.

Mucoid effusions blocked bacterial attachment significantly better than did effusions of lower viscosity. Mucins have been found to be the only single determinant of viscosity in middle ear fluid [11]. Furthermore, we found that the high-molecular-weight fraction of the MEEs, which comprises the mucin glycoprotein, blocked bacterial adherence up to the same level as did the complete effusions. This effect, however, only occurred in the presence of sialic acid, for after its removal, no inhibition was found. Free sialic acid on its own did not have any effect on bacterial adherence, nor did any of the other negatively charged molecules that were used as potential inhibitors in the adherence assay. These findings suggest that only mucin-bound sialic acid inhibits bacterial adhesion by means of structural interference rather than because of its negative charge. Thus, sialylated mucin appears to act as a receptor analog. 
Binding of Hi to mucin has been shown to be mediated by outer membrane proteins (OMPs) P2, P5 and another not yet identified protein $[25,31,32]$. Furthermore, Reddy et al. demonstrated that the removal of sialic acid of human pharyngeal mucin and human middle ear mucin, respectively, resulted in a loss of binding to OMPs of $H$. influenzae. Our results corroborate these results and are in agreement with those of several other studies that found oligosacchrides of mucin containing sialic acid to be receptors for NTHi. Additionally, we found a positive correlation between the degree of inhibition and the sialic acid content of the effusion, which strongly suggests that the sialic acid molecules are involved in the process of adherence.

St. Geme [33] has found that the HMW1 adhesion of NTHi interacts with a sialylated glycoprotein receptor on the surface of cultured human epithelial cells, which could be the adhesive site that is blocked by mucin.

Our data support the notion that in the presence of effusion in the middle ear space, bacteria attached to mucin may be cleared through various mechanisms of eradication such as mucociliary clearance, phagocytosis and destruction within neutrophils, lysis by inflammatory byproducts outside the cells and immunologic destruction by antibody and complement. The antimicrobial factors involved in this process include the accumulation of monocytes, plasmacells, macrophages and leucocytes within the middle ear fluid as well as a high concentration of lysozyme, lactoferrin, defensins and surfactant proteins A and D [7, 34]. These mechanisms seem to act synergistically in resolving middle ear effusions and could explain why most of the effusions do not reveal any culturable bacteria (92\% in this study).

IgA may possibly play an additional role in the prevention of infection not only by specific neutralization of pathogens, but also by Fab-independent mechanisms via bacterial adhesion to sialyloligosaccharide molecules on secretory immunoglobulin A [35].

We have demonstrated that both pilus-dependent attachment of Hib and non-pilus-dependent binding of NTHi to epithelial cells can be blocked by MEE mucins and that this inhibition is mediated by specific mechanisms. The antiadhesive effect of high-molecular sialylated glycoproteins like mucins could be utilized to reduce the bacterial colonization of mucosal surfaces, which is the necessary prerequisite in the course of infection.

Acknowledgement The authors wish to thank Dr. Rainer R. Willers, Department of Computer Science, Heinrich Heine University, Düsseldorf, Germany, for performing the statistical analysis. We also thank Dr. H. Warnebier, Department of Otorhinolaryngology, EVK Düsseldorf, Germany, and Dr. C. Birken, ENT Specialist, Düsseldorf, Germany, for providing MEE samples.

\section{References}

1. Davidson J, Hyde ML, Alberti PW (1989) Epidemiologic patterns in childhood hearing loss: a review. Int J Pediatr Otorhinolaryngol 17: 239-266

2. Kubba H, Pearson JP, Birchall JP (2000) The aetiology of otitis media with effusion: a review. Clin Otolaryngol 25: 181-194
3. Jero J, Karma P (1997) Bacteriological findings and persistence of middle ear effusion in otitis media with effusion. Acta Otolaryngol (Stockh) 529: 22-26

4. Hunter SE, Singla AK, Prazma J, Jewett BS, Randell SH, Pillsbury HC (1999) Mucin production in the middle ear in response to lipopolysaccharides. Otolaryngol Head Neck Surg 120: $884-888$

5. Rose AS, Prazma J, Randell SH, Baggett HC, Lane AP, Pillsbury HC (1997) Nitric oxide mediates mucin secretion in endotoxin-induced otitis media with effusion. Otolaryngol Head Neck Surg 116: 308-316

6. Smirnova MG, Birchall JP, Pearson JP (2000) Tnf-alpha in the regulation of MUC5AC secretion: some aspects of cytokine-induced mucin hypersecretion on the in vitro model. Cytokine 12: $1732-1736$

7. Arnold W (1977) Reaktionsformen der Mittelohrschleimhaut. Arch Otorhinolaryngol 216: 369-473

8. Hutton DA, Fogg FJJ, Murty G, Birchall JP, Pearson JP (1993) Preliminary characterization of mucin from effusions of cleft palate patients. Otolaryngol Head Neck Surg 109: 1000-1006

9. Siirala U (1956) The problem of sterile otitis media. Prac Otorhinolaryngol 19: 159-169

10. Yamanaka N, Hotomi M, Shimada J, Togawa A (1997) Immunological deficiency in "otitis-prone" children. Ann N Y Sci 830: 70-81

11. Carrie S, Hutton DA, Birchall JP, Green GGR, Pearson JP (1992) Otitis media with effusion: components which contribute to the viscous properties. Acta Otolaryngol (Stockh) 112: 504-511

12. Clemans DL, Marrs CF, Patel M, Duncan M, Gilsdorf JR (1998) Comparative analysis of Haemophilus influanzae hifA (Pilin) genes. Infect Immun 66: 656-663

13. McCrea KW, St. Sauver JL, Marrs CF, Clemans D, Gilsdorf JR (1998) Immunologic and structural relationship of the minor pilus subunits among Haemophilus influenzae isolates. Infect Immun 66: 4788-4796

14. Andersson B, Porras O, Hanson LA, Lagergard T, SvanborgEden C (1986) Inhibition of attachment of Streptococcus pneumoniae and Haemophilus influenzae by human milk and receptor oligosaccharides. J Inf Dis 153: 232-237

15. Lowry OH, Rosenbrough NJ, Farr AL, Randall RJ (1951) Protein measurement with the Folin phenol reagent. J Biol Chem 93: $265-275$

16. Bhavanandan VP, Sheykhnazari M (1993) Adaptation of the Periodate-Resorcinol method for determination of sialic acids to a microassay using microtiter plate reader. Anal Biochem 213: 438-440

17. Hanisch FG, Hanski C, Hasegawa A (1992) Lewis x antigen as defined by monoclonal antibody AM-3 is a marker of dysplasia in the colonic adenoma-carcinoma sequence. Cancer Res 52: 3138-3144

18. Müller S, Goletz S, Packer N, Gooley A, Lawson AM, Hanisch FG (1997) Localization of O-glycosylation sites on glycopeptide fragments from lactation-associated MUC1. All putative sites within the tandem repeat are glycosylation targets in vivo. J Biol Chem 272: 24780-24793

19. Uhlenbruck G, Rothe A, Pardoe GI (1968) Noteworthy chemical, serologic and electrokinetic phenomena in cat erythrocytes: a contribution to the determination and importance of mucoid and glycolipoid bound erythrocyte neuraminic acid. Z Immunitatsforsch Allerg Klin Immunol 136: 79-97

20. Giebink GS, Juhn SK, Weber ML, Le CT (1982) The bacteriology and cytology of chronic otitis media with effusion. Pediatr Infect Dis 1: 98-103

21. Hinton A, Herdman RC, Hartley C, O'Keefe L (1996) The incidence of bacteria in middle ear effusions. Clin Otolaryngol 21: $158-161$

22. Ovesen T, Ledet T (1992) Bacteria and endotoxin in middle ear fluid and the course of secretory otitis media. Clin Otolaryngol 17: $531-534$ 
23. Schroten H, Hanisch FG, Plogmann R, Hacker J, Uhlenbruck G, Nobis-Bosch R, Wahn V (1992) Inhibition of adhesion of S-fimbriated E.coli to buccal epithelial cells by human milk fat globule membrane components: A novel aspect of the protective function of mucins in the nonimmunoglobuline fraction. Infect Immun 60: 2893-2899

24. Kubiet M, Ramphal R, Weber A, Smith A (2000) Pilus-mediated adherence of Haemophilus influenzae to human respiratory mucins. Infect Immun 68: 3362-3367

25. Reddy MS, Bernstein JM, Murphy TF, Faden HS (1996) Binding between outer membrane proteins of nontypeable Haemophilus influenzae and human nasopharyngeal mucin. Infect Immun 64: 1477-1479

26. Vered J, Eliezer N, Sade J (1972) Biochemical characterization of middle ear effusions. Ann Otol Rhinol Laryngol 81: 394400

27. Hanisch FG, Müller S (2000) MUC1: The polymorphic appearance of a human mucin. Glycobiol 10: 439-449

28. Hutton DA, Guo L, Birchall JP, Severn TL, Pearson JP (1998) MUC5B expression in middle ear mucosal glands. Biochem Soc Trans 26: S117

29. Davies J, Carlstedt I, Nilsson AK, Hakansson A, Sabharwal H, van Alphen L, van Ham M, Svanborg C (1995) Binding of Haemophilus influenzae to purified mucins from the human respiratory tract. Infect Immun 63: 2485-2492
30. Sheehan JK, Thornton DJ, Somerville M, Carlstedt I (1991) The structure and heterogeneity of respiratory tract mucus glycoproteins. Am Rev Respir Dis 144: S4-9

31. Reddy MS, Murphy TF, Faden HS, Bernstein JM (1997) Middle ear mucin glycoprotein: Purification and interaction with nontypable Haemophilus influenzae and Moraxella catarrhalis. Otolaryngol Head Neck Surg 116: 175-181

32. Bernstein JM, Reddy M (2000) Bacteria-mucin interaction in the upper aerodigestive tract shows striking heterogeneity: Implications in otitis media, rhinosinusitis, and pneumonia. Otolaryngol Head Neck Surg 122: 514-520

33. St Geme JW 3rd (1994) The HMW1 adhesin of nontypable Haemophilus influenzae recognizes sialated glycoprotein receptors on cultured human epithelial cells. Inf Immun 62: 3881-3889

34. Lim DJ, Chun YM, Lee HY, Moon SK, Chang KH, Li JD, Andalibi A (2000) Cell biology of tubotympanum in relation to pathogenesis of otitis media- a review. Vaccine 19: S17-25

35. Schroten H, Stapper C, Plogmann R, Köhler H, Hacker J, Hanisch FG (1998) Fab-independent antiadhesion effects of secretory immunglobulin A on S-fimbriated E. coli are mediated by sialyloligosaccharides. Inf Immun 66: 3971-3973 